\title{
Research of Tourism Destination Image Based on Web Text: a Case Study of Yellow Crane Tower*
}

\author{
Xiaoyan Liu \\ School of Business Administration \\ Jianghan University \\ Wuhan, China
}

\author{
Qianqian $\mathrm{Gu}$ \\ School of Business Administration \\ Jianghan University \\ Wuhan, China
}

\begin{abstract}
This paper takes the Yellow Crane Tower as the research object, uses the network crawler program, collects the scenic spot official propaganda image and the domestic traveling website community to publish the tourist comment content, unifies the SPSS/EXCEL statistical analysis method and the text analysis method, using ROST CM6 software to identify the perceived image and propaganda image of Yellow Crane Tower Scenic, and further using IPA model to obtain the similarities and differences between the propaganda image and the perceived image and find out the reasons. Based on this, this paper provides strategies for the positioning and sustainable evolution of tourism destination image from three aspects: holistic tourism, cultural tourism integration and experience tourism.
\end{abstract} IPA

Keywords-web text; Yellow Crane Tower; destination image;

\section{INTRODUCTION}

As time goes, Internet has enabled us to obtain outside information without leaving home, and netizens have changed from passively accepting information to actively collecting and publishing information. Tourists share travel experiences, exchange transportation, travel methods, inquiries about tourist routes, tourist destinations, and so on. Therefore, the role of web texts is becoming more and more obvious, and it is gradually being used by researchers in the study of the perception of tourist destinations.

Taking the Yellow Crane Tower scenic spot as an example, this study uses the Octopus data collection tool to collect the officially designed publicity image network text of the Yellow Crane Tower Scenic Spot and the network image of the tourist image of the tourist travels. The fourquadrant depth is carried out through the ROST CM6 software. Analyzing and systematically summarizing the similarities and differences between the tourist destination tourism image and the tourists' actual perception image, so as to provide appropriate suggestions for the official image design of the scenic spot to help optimize and improve its tourism image.

*Fund: the paper was funded by the Doctoral Research Project of Jianghan University "Research on Online Word of Mouth Communication under Tourism Destination context".

\section{THEORETICAL BACKGROUND}

Barich and Kolter (1991) divided the destination image into a launching image and a receptive image. The former is the destination to actively convey its image to the tourists, while the latter is the perceived image of the tourists after the field tour. Relevant scholars gradually began to use the online text content such as travel commentary or travel guide to explore the behavior of tourists and the image recognition characteristics of tourism. Stepchenkova and Morrison (2006) conducted a comparative study based on the image of American tourism, and believed that the content of network communication would affect the tourism image of Russian countries; Zhang.et.al (2011) analyzed the relevant network logs and found that cultural heritage and geological resources Huashan Scenic. Wang and Chen (2017) deeply explored the image perception characteristics and evaluation of Weizhou Island based on the short commentary texts of tourists. Yang and Zhang (2017) used the travel comments from ctrip as an example to find that Tianmu Mountain's Image perception of tourists presents a positive trend.

Based on this, this paper will use the text analysis method, combined with the Octopus network data collection tool, ROST CM6 software to analyze the tourism propaganda image and the Yellow Crane Tower scenic spot. This paper also puts forward reasonable opinions on the image design of tourism destinations, and helps to optimize and improve the image of tourism destinations.

\section{RESEARCH OBJECTS AND METHODS}

\section{A. Research Object}

The Yellow Crane Tower is located at the foot of the Snake Mountain in Wuhan, Hubei Province, China. It was built in the second year of Dongwu, 223 AD. It is known as the "Three Famous Buildings in the South of the Yangtze River" with the Yueyang Tower of Hunan and the Tengwang Pavilion of Jiangxi.

\section{B. Research Methods}

This paper uses the network text analysis method to collect information sources such as web pages, forums, blogs, travel notes, and guides through big data collectors, using ROST CONTNET MINING (referred to as ROST CM6) to 
find the similarities and differences between the destination propaganda image and the perceived image.

\section{Data Gathering}

The research data comes from two parts as shown in "Table I". The first part is the official propaganda data of the network media of the Yellow Crane Tower Scenic Area, mainly from the official website of the Yellow Crane Tower, the relevant websites of the Wuhan Municipal Government and the tourism department, and the Yellow Crane Tower Scenic Area, and 102 articles were collected. The second part is the 20,400 raw data of Yellow Crane Tower Scenic Spot on Baidu Tourism, Qunar.com, and other famous travel websites, 20,400 original data on the hornet's nest and other famous tourist sites, covering the period from April 2015 to April 2018, after screening, the effective data is 10,979.

TABLE I. SOURCE OF TEXT DATA

\begin{tabular}{|c|l|l|}
\hline & $\begin{array}{l}\text { Official propaganda image of the Yellow Crane } \\
\text { Tower }\end{array}$ & $\begin{array}{l}\text { Tourist perception of Yellow Crane } \\
\text { Tower }\end{array}$ \\
\hline Text data source & $\begin{array}{l}\text { the official website of the Yellow Crane Tower, } \\
\text { Ctrip, eLong, Qunar, etc. }\end{array}$ & $\begin{array}{l}\text { Baidu Travel, Qunar.com, Ma } \\
\text { Honeycomb's Visitor Evaluation section }\end{array}$ \\
\hline Total text entry (valid) & 102 & 10979 \\
\hline
\end{tabular}

Through the Octopus data capture tool, the official propaganda data of the Yellow Crane Tower Scenic Spot and the effective tourist perception data of the typical website are separately sorted and imported into the ROST software for segmentation analysis.

\section{DATA ANALYSIS}

\section{A. Word Frequency Analysis}

Using the words after the word segmentation, the word frequency analysis is carried out to obtain the high-frequency word statistics of the tourism publicity image of Yellow Crane Tower Scenic Area (see "Table II") and the highfrequency word statistics of the tourist perception image (see "Table III").

TABLE II. High-Frequency Words Statistics of Propaganda IMAGE ON Yellow CRANE Tower

\begin{tabular}{|c|c|c|c|c|c|c|c|c|c|}
\hline Vocabulary & $\begin{array}{l}\text { Word } \\
\text { frequency }\end{array}$ & Vocabulary & $\begin{array}{c}\text { Word } \\
\text { frequency }\end{array}$ & Vocabulary & $\begin{array}{c}\text { Word } \\
\text { frequency }\end{array}$ & Vocabulary & $\begin{array}{c}\text { Word } \\
\text { frequency }\end{array}$ & Vocabulary & $\begin{array}{c}\text { Word } \\
\text { frequency }\end{array}$ \\
\hline $\begin{array}{c}\text { Yellow Crane } \\
\text { Tower }\end{array}$ & 191 & Founded & 12 & Glazed tile & 7 & $\begin{array}{l}\text { Thousand } \\
\text { years }\end{array}$ & 5 & And beauty & 4 \\
\hline Wuhan & 43 & military & 12 & $\begin{array}{l}\text { Tang } \\
\text { Dynasty }\end{array}$ & 7 & Jiangcheng & 5 & Reiki & 4 \\
\hline Poetry & 42 & $\begin{array}{l}\text { White } \\
\text { clouds }\end{array}$ & 11 & $\begin{array}{l}\text { Bottom } \\
\text { layer }\end{array}$ & 7 & Make up & 5 & Ascend & 4 \\
\hline Wuchang & 27 & Bridge & 11 & Three towns & 7 & country & 5 & Population & 4 \\
\hline building & 24 & And called & 10 & mural & 7 & Ink & 5 & Close & 4 \\
\hline Yangtze & 24 & country & 10 & Resort & 6 & Literati & 5 & flat & 4 \\
\hline Park & 20 & Attractions & 10 & Far from & 6 & Couplet & 5 & charm & 4 \\
\hline Scenic spot & 20 & Cui Wei & 10 & Old site & 6 & magnificent & 5 & delicate & 4 \\
\hline China & 17 & pagoda & 9 & hall & 6 & Boutique & 5 & style & 4 \\
\hline $\begin{array}{l}\text { Famous } \\
\text { building }\end{array}$ & 17 & Male & 9 & Scenery & 6 & Jiang Shang & 5 & Reputation & 4 \\
\hline $\begin{array}{c}\text { Three } \\
\text { countries }\end{array}$ & 16 & culture & 9 & tour & 6 & Beautiful & 5 & Guqin & 4 \\
\hline Three major & 16 & history & 8 & legend & 6 & classical & 5 & Charm & 4 \\
\hline Tourism & 16 & soul & 8 & Roof & 6 & $\begin{array}{l}\text { Eternal } \\
\text { swan }\end{array}$ & 5 & $\begin{array}{l}\text { Ancient } \\
\text { architecture }\end{array}$ & 4 \\
\hline $\begin{array}{l}\text { Yueyang } \\
\text { Tower }\end{array}$ & 16 & poet & 8 & Li Bai & 6 & Warp angle & 5 & century & 3 \\
\hline reconstruction & 16 & $\begin{array}{l}\text { Famous } \\
\text { place }\end{array}$ & 8 & Fly & 6 & Full view & 5 & Iconic & 3 \\
\hline Historical & 14 & modern & 8 & celebrity & 6 & Grass & 5 & Four names & 3 \\
\hline Main building & 13 & Imagery & 8 & Archway & 6 & famous & 5 & Characteristic & 3 \\
\hline Jiangnan & 12 & Jiangxi & 7 & Ticket & 5 & Famous & 4 & $\begin{array}{l}\text { Wood } \\
\text { structure }\end{array}$ & 3 \\
\hline The world & 12 & design & 7 & natural & 5 & $\begin{array}{l}\text { Cultural } \\
\text { relics }\end{array}$ & 4 & Beautiful & 2 \\
\hline
\end{tabular}


TABLE III. High-FREQUENCY WordS Statistics OF PERCEIVED IMAGE ON Yellow CRANE TOWER

\begin{tabular}{|c|c|c|c|c|c|c|c|c|c|}
\hline Vocabulary & $\begin{array}{c}\text { Word } \\
\text { frequency }\end{array}$ & Vocabulary & $\begin{array}{c}\text { Word } \\
\text { frequency }\end{array}$ & Vocabulary & $\begin{array}{c}\text { Word } \\
\text { frequency }\end{array}$ & Vocabulary & $\begin{array}{c}\text { Word } \\
\text { frequency }\end{array}$ & Vocabulary & $\begin{array}{c}\text { Word } \\
\text { frequency }\end{array}$ \\
\hline $\begin{array}{l}\text { Yellow Crane } \\
\text { Tower }\end{array}$ & 7313 & culture & 324 & tourism & 232 & Imagine & 135 & Guishan & 93 \\
\hline Wuhan & 2993 & Spectacular & 324 & Wuchang & 232 & Disappointed & 135 & impression & 93 \\
\hline Attractions & 2508 & The world & 318 & Overlooking & 227 & Scenery & 130 & Bus & 92 \\
\hline Yangtze & 2132 & Cheap & 318 & Iconic & 219 & Full view & 129 & Monument & 91 \\
\hline Ticket & 1601 & regret & 297 & play & 160 & That's it & 128 & model & 91 \\
\hline Worth going & 1388 & elevator & 296 & $\begin{array}{l}\text { Yueyang } \\
\text { Tower }\end{array}$ & 160 & Half price & 126 & snack & 91 \\
\hline Bridge & 1209 & East Gate & 294 & $\begin{array}{l}\text { Thousand } \\
\text { years }\end{array}$ & 160 & Not big & 104 & stairs & 78 \\
\hline Convenience & 1141 & Far from & 292 & South gate & 158 & Top & 104 & Founded & 78 \\
\hline Building & 896 & Fun & 288 & friend & 157 & attitude & 101 & Riverside & 78 \\
\hline $\begin{array}{l}\text { Famous } \\
\text { building }\end{array}$ & 716 & Hubu Lane & 284 & the weather & 157 & breath & 101 & $\begin{array}{l}\text { Hubei } \\
\text { Province }\end{array}$ & 77 \\
\hline Landscape & 642 & regret & 278 & Lookout & 156 & explain & 100 & Connotation & 76 \\
\hline Yellow crane & 629 & landmark & 271 & majestic & 156 & $\begin{array}{l}\text { Beautiful } \\
\text { view }\end{array}$ & 98 & Surrounding & 76 \\
\hline History & 606 & service & 261 & poet & 150 & Ink & 97 & that's it & 76 \\
\hline Reconstruction & 421 & Fame & 261 & Li Bai & 145 & Passing by & 97 & Original site & 75 \\
\hline Three major & 416 & not worth & 244 & Three towns & 143 & at night & 97 & Guqin & 75 \\
\hline Decoration & 382 & Big four & 240 & Literati & 142 & momentum & 96 & $\begin{array}{l}\text { The world's } \\
\text { first }\end{array}$ & 74 \\
\hline Service & 356 & Suggest & 237 & tour & 138 & traffic & 95 & style & 74 \\
\hline Park & 353 & unfortunately & 232 & Visit & 137 & the best & 95 & Cui Wei & 74 \\
\hline Jiangnan & 337 & country & 232 & $\begin{array}{l}\text { Ascend to } \\
\text { the top }\end{array}$ & 137 & Hubei & 93 & $\begin{array}{l}\text { Four } \\
\text { famous } \\
\text { buildings }\end{array}$ & 73 \\
\hline
\end{tabular}

\section{B. Parts of Speech Analysis}

From the perspective of part of speech (see "Table IV"), the propaganda image of the scenic spot of Yellow Crane Tower and the part of the perceptual image of tourists have a $2 \%$ difference in nouns, and the perceived image is less than $2 \%$, mainly composed of scenic spots and derivatives of the Yellow Crane Tower; on tourists 'image in higher than official propaganda image of $5.5 \%$, mainly reflecting the details of the flow of tourists and tourism process; on the adjective, tourists' image vocabulary below the official propaganda image of $3.5 \%$, mainly reflecting the administration with the summary and generalization of local tourism characteristics, there are more negative vocabulary in the perception of tourists.

TABLE IV. The PARTS OF SPEECH ANALySIS

\begin{tabular}{|c|c|c|}
\hline Project & Promotional Image of Yellow Crane Tower & Perception Image of Yellow River Tower \\
\hline \multirow[t]{2}{*}{ Noun } & 57, accounting for $60 \%$ & 55 , accounting for $58 \%$ \\
\hline & $\begin{array}{l}\text { Such as the Yellow Crane Tower, ancient } \\
\text { architecture, Cui Wei, scenery and other words }\end{array}$ & $\begin{array}{l}\text { Such as Yellow Crane Tower, Bridge, Yangtze River, } \\
\text { Hubu Lane, Guishan and other words }\end{array}$ \\
\hline \multirow[t]{2}{*}{ Verb } & 10 , accounting for $10.5 \%$ & 15 , accounting for $16 \%$ \\
\hline & Such as reconstruction, vision, tour and other words & $\begin{array}{l}\text { Such as overlooking, reconstructing, overlooking, } \\
\text { ascending and looking up }\end{array}$ \\
\hline \multirow[t]{2}{*}{ Adjective } & 28 , accounting for $29.5 \%$ & 25 , accounting for $26 \%$ \\
\hline & $\begin{array}{l}\text { Words such as majestic, magnificent, fine, } \\
\text { exquisite, and popular }\end{array}$ & Such as not worth, best, just like, regret, worth going, etc. \\
\hline
\end{tabular}

\section{Propaganda of the Yellow Crane Tower Scenic Spot: Analysis of Common Words of Perceived Image}

Taking the official propaganda image of the Yellow Crane Tower scenic spot as a comparison object, it is found that 34 vocabulary of the tourist perception image overlaps with the official propaganda image (see "Table V"), occupying about $36 \%$ of the statistical table. The frequencies of Yellow Crane Tower, Wuhan, scenic spots, Yangtze River, tickets, bridges, buildings, famous buildings, history, reconstruction, etc. appear much higher than other words, reflecting the fact that the Yellow Crane Tower, the Yangtze River and the bridge have become the symbol of Wuhan. Sex elements form the true characteristics of Wuhan tourism, which is not only the consensus of tourism enterprises and government agencies, but also highly recognized by tourists. From the perspective of part of speech and category, common high-frequency words are mostly composed of 
nouns, such as the Yangtze River, the bridge, the park, Wuchang, Libai, Sanzhen, Wenren, Moke, Cui Wei. In addition to nouns, there are some summary adjectives, such as iconic, famous buildings, the world, thousands of loads, etc., as well as some verbs highlighting the location and appreciation of the Yellow Crane Tower, such as overlooking.

TABLE V. SAme And DifFEREnT Words Between Propaganda Image And Perceived Image

\begin{tabular}{|c|c|c|}
\hline Same Words & Different Words of Propaganda Image & Different Words of perceived Image \\
\hline $\begin{array}{l}\text { Yellow Crane Tower, Wuhan } \\
\text { Attractions, Yangtze River, } \\
\text { Ticket Bridge, Buildings, } \\
\text { Historical Reconstruction, } \\
\text { Three Great Parks, Tourism } \\
\text { Wuchang iconic, Yueyang } \\
\text { Tower, Poets Li Bai, Three } \\
\text { Town, Literati, Visiting the } \\
\text { scenery }\end{array}$ & $\begin{array}{l}\text { mind, the modern image, the Jiangxi design, the } \\
\text { glazed tile, the Tang Dynasty, the bottom layer of the } \\
\text { murals, the old site, the legendary roof, the flying } \\
\text { celebrity, the celebrity archway, the natural city, the } \\
\text { beautiful, the beautiful, the river, the beautiful, the } \\
\text { ancient, the eternal singer, the famous singularity, the } \\
\text { famous reputation. Cultural relics and beautiful spirits } \\
\text { ascend to the heights of the population, close to the } \\
\text { plane, the charm, the exquisite reputation, the ancient } \\
\text { architecture, the four famous buildings, the famous } \\
\text { wooden structure, the beautiful }\end{array}$ & $\begin{array}{l}\text { Worth a visit, convenient scenery, Yellow crane } \\
\text { decoration, spectacular, cheap, regret, elevator, East } \\
\text { Gate, fun, household, alley, regret, landmark service, } \\
\text { fame, not worthy of the four recommendations, but } \\
\text { unfortunately overlooking the South Gate friends, the } \\
\text { weather, the majestic visit, ascending to the horizon, the } \\
\text { disappointment, the half price is not too big. Attitude } \\
\text { and atmosphere to explain the beauty of the road } \\
\text { through the evening, the best traffic, Hubei, Guishan, } \\
\text { impression, bus, monument, model, snack, stairway, the } \\
\text { edge of the river, Hubei Province, the surrounding area, } \\
\text { the original site of the world's first four famous } \\
\text { buildings }\end{array}$ \\
\hline
\end{tabular}

\section{Analysis of Propaganda-perceived Image Differences}

In the statistics of the high-frequency words of the network text of the propaganda image attribute of the Yellow Crane Tower, the word vocabulary with the difference of the propaganda image is obtained (see "Table V"). From the perspective of part of speech and category, this table is mainly composed of five parts. One is historical and cultural nouns, such as poetry, three countries, murals, Tang Dynasty, legends, couplets, cultural relics, and centuries; secondly, the related nouns of scenic spots, such as the main building, pagodas, glazed tiles, halls, roofs, flying plaques, arches, etc.; the third is the description of adjectives such as heroes, magnificence, classical, famous, popular, ingenious, etc.; the fourth is the macro description of terms such as China, the country and Jiangcheng etc.; the fifth is to summarize the adjectives, such as modern, natural and so on.

From the perspective of part of speech and category, this table is mainly composed of five parts (see "Table V"). The first is emotional adjectives, such as worthy of a visit, regret, regret, worthless, unfortunate, disappointing, and so on. Secondly, tourists are perceptive adjectives, such as convenience. Spectacular, cheap, fun, best, etc.; the third is to visit scenic nouns such as Yellow Crane, Dongmen, Hubu
Alley, Landmark, South Gate, Guishan, etc.; the fourth is the movement and detail words during the tour, such as overlooking, play, look, visit, ascend to the distance, etc.; the fifth is the tourism public service perception term, such as elevators, services, explanations, transportation, public transport and so on.

\section{E. Tourist Perception Satisfaction Analysis}

The ROST CM6 software can be used to analyze the data of the visitors' perception network text, and the sentiment analysis conclusions can be obtained (see "Table VI"). After tourists visited Yellow Crane Tower, the positive sentiment reached $40 \%$, which was much higher than the $14 \%$ of the negative emotions. This indicates that tourists are more satisfied with the tourism of Yellow Crane Tower and have a stronger sense of tourism image. However, it should not be overlooked that in the classification of negative emotions, the highly negative classification is far superior to the general, which means that the unsatisfied people who come to the Yellow Crane Tower scenic spot tend to be highly dissatisfied.

TABLE VI. SENTIMENT ANALysis OF Network TeXt DATA ON PERCEIVEd IMAGE

\begin{tabular}{|l|l|l|}
\hline \multicolumn{1}{|c|}{ Emotional type Quantity } & \multicolumn{1}{c|}{ Percentage } \\
\hline Positive emotion & \multicolumn{1}{|c|}{ Q391 } & $40 \%$ \\
\hline Neutral mood & 5050 & $46 \%$ \\
\hline Negative emotion & 1538 & $14 \%$ \\
\hline Positive emotional segmentation statistics & \multicolumn{2}{|l|}{} \\
\hline General & 1405 & $32 \%$ \\
\hline Moderate & 1271 & $29 \%$ \\
\hline Height & 1715 & $39 \%$ \\
\hline Negative emotion segmentation statistics & 354 & $23 \%$ \\
\hline General & 584 & $38 \%$ \\
\hline Moderate & 600 & $39 \%$ \\
\hline Height &
\end{tabular}




\section{CONCLUSION}

\section{A. Global Tourism Management Cooperation Mechanism}

In the follow-up development process, such landmarks as the Yellow Crane Tower can be used in the planning and construction of scenic spots, urban environmental improvement, tourism supporting facilities, tourism management services, tourism promotion and other aspects to strengthen the construction of core scenic spots. It has become a magnet for global tourism, driving the cluster development of surrounding industries and exerting the comprehensive driving effect of the core scenic spots.

\section{B. Exploring Deep Integration of Culture and Tourism}

For example, such as the Yellow Crane Tower, the author proposes to integrate cultural elements into tourism products, or to realize the penetration of the tourism industry into the cultural industry. Through the complementation of industrial functions, the integration of culture can be deepened and tourism to create a high-end cultural tourism brand can be realized to change the scenic spot's (point) lacking the status quo of entertainment projects, enhance the value of the tourism industry, and achieve sustainable tourism development.

\section{Promoting the New Development of Experiential Tourism}

With the increase of tourism experience and the change of tourism awareness, tourists are no longer satisfied with the traditional tourism and sightseeing mode, they want to participate in it, and this tourism mode is in line with the characteristics of experience tourism. Taking the Yellow Crane Tower as an example, it is possible to combine the construction of the Yangtze River main axis and promote the construction of the riverside ecological landscape tourism belt such as the right bank avenue, the landscape balcony, the river beach park, and the railway ruins cultural park to construct a modern urban experience zone.

\section{REFERENCES}

[1] Hsu,C.H.C., Song,H. Projected images of major Chinese outbound destinations [J]. Asia Pacific Journal of Tourism Research.2012,17(5),577-593

[2] Huang, S., Gross, M.J. Australia's destination image among mainland chinese cravelers:An ex-ploratory study [J]. Journal of Travel \& Tourism Marketing. 2010, 27(1),63-81.

[3] Stepchenkova, S., A. M. Morrison. Russia's destination damage among American pleasure travelers:Revisiting Echtner \& Ritchie [J]. Tourism Management, 2008, 29(3): 548-560.

[4] Hunt J D. Image As a Factor in Tourism Development [J]. Tourism Recreation Research, 2016, 13(3):1-7.

[5] Crompton J L. An assessment of the image of Mexico as a vacation destination and the influence of geographical location upon that image [J]. Journal of Travel Research, 1979, 17(4):18-23.

[6] Fakeye P C, Crompton J L. Image differences between prospective, first-time, and repeat visitors to the lower Rio Grande Valley [J]. Journal of Travel Research, 1991, 30(2): 10-16.
[7] Tasci, A. D. A, Gartner W C, Cavusgil, S. T. Conceptualization and operationalization of destination image [J]. Journal of Hospitality \& Tourism Research, 2007, 31(2): 194-223.

[8] Gunn C. Vacationscape: Designing Tourist Regions [M]. The University of Texas at Austin, 1972.

[9] Barich H, Kotler P. A framework for marketing image management [J]. Sloan Manage Rev, 1991, 32(2): 94-104.

[10] Grosspietsch M. Perceived and projected images of Rwanda: Visitor and international tour operator perspectives. Tourism Management, 2006, 27: 225-234 